\title{
Enantioselective Redox-Neutral Coupling of Aldehydes and Alkenes by an Iron-Catalyzed "Catch-Release" Tethering Approach
}

\author{
Jing Li, ${ }^{\dagger}$ Alexander Preinfalk, ${ }^{\dagger}$ and Nuno Maulide*(1) \\ Institute of Organic Chemistry, University of Vienna, Währinger Strasse 38, 1090 Vienna, Austria
}

Supporting Information

ABSTRACT: The reductive coupling of aldehydes and alkenes is an emerging technology that holds the potential to reinvent carbonyl addition chemistry. However, existing enantioselective methods are limited to form "branched" products. Herein, we present a directed enantio- and diastereoselective alkylation of aldehydes with simple olefins to selectively yield linear coupling products. This is achieved by redox-neutral remote functionalization, whereby a tethering "catch-release" strategy decisively solves the key problems of reactivity and selectivity.

I $\mathrm{n}$ recent years, coupling approaches combining aldehydes and alkenes, readily available feedstocks, have started to emerge as an appealing alternative to classical carbonyl addition reactions (Figure 1a). ${ }^{1}$ Krische and co-workers pioneered the development of both hydrogenative and transfer hydrogenative couplings of carbonyl compounds with a variety of unsaturated compounds, including enones, ${ }^{2 a}$ alkynes, ${ }^{2 b} 1,3-$ dienes, ${ }^{2 \mathrm{c}}$ enynes, ${ }^{2 \mathrm{~d}}$ allenes, ${ }^{2 \mathrm{e}}$ and allyl compounds ${ }^{2 \mathrm{f}}$ yielding the corresponding branched coupling products. Additionally, Buchwald and co-workers developed the asymmetric addition of alkene-derived nucleophiles to ketones and leading exclusively to the branched products. ${ }^{3}$ However, enantioselective methods to access the complementary, highly valuable linear products (Figure 1b) using a direct redox-neutral coupling of olefins have not yet been developed. ${ }^{4-6}$

As part of our group's ongoing research on chirality transfer processes, ${ }^{7}$ we became interested in accessing these scaffolds from readily available chiral building blocks. We therefore envisioned an enantioselective redox-neutral coupling that would take advantage of a carbocationic mechanism to ensure complete selectivity for the linear coupling product (Figure 1b). To overcome the low intrinsic nucleophilicity of unactivated alkenes, ${ }^{6}$ we decided to employ a "catch-release" tethering group approach (Figure 1c). ${ }^{8}$ Under Lewis-acid catalysis, the alcohol moiety on the substrate 1 would serve as anchoring point for the aldehyde reaction partner, reversibly forming an oxocarbenium ion A (cf. Figure 1c). By virtue of tethering, attack of the alkene partner onto this highly electrophilic species becomes intramolecular, thus circumventing reactivity issues and leading to a cyclic, tertiary carbocation B. In order to evade the potential deleterious side reactions typical of carbocationic intermediates, ${ }^{9,10}$ a designed 1,5-hydride shift event ${ }^{11}$ would not only allow convergence to a stabilized oxacarbenium ion $\mathbf{C}$ but also ensure the formal reduction of carbocation $\mathbf{B}$. Hydrolysis of $\mathbf{C}$ would then achieve a "release" event and yield the desired linear coupling motif.

Herein we present our reduction of this concept to practice in an asymmetric synthesis of linear aldehyde-alkene coupling motifs by redox-neutral remote functionalization under iron catalysis, featuring the possibility of forming two new challenging chiral centers starting from a single, readily chiral-pool derived, stereogenic element.

At the onset of our investigation, we tested several unsaturated alcohols 1, differing in the length of the spacing carbon-chain (Table 1, entries 1-3), as alkene partners. After some initial experimentation with aldehyde $\mathbf{2 a}$ as model electrophile, we identified $\mathrm{SnCl}_{4}$ as a suitable Lewis Acid. To our delight, alcohol 1a (with 3 methylene units between the carbinol and the alkene) showed promising reactivity and already excellent levels of diastereoselectivity of the final product 3a, carrying 2 stereogenic centers in a 1,3-relationship. This substrate mechanistically implies the transient formation of an eight-membered ring (cf. intermediate $\mathbf{B}$ in Figure 1). Encouraged by these promising initial results, we continued with substrates $\mathbf{1 a}$ and $\mathbf{2 a}$ for further optimization. Changing the amount of tin(IV) chloride led to worse results (entries 4 and 5). While investigating other Lewis acids (entries 6-9), we identified iron(III) chloride as a uniquely effective catalyst for this reaction. Increasing the temperature from room temperature to $100{ }^{\circ} \mathrm{C}$ resulted in better yield and remarkably short reaction times (entry 10). Notably, product 3a was obtained as virtually a single enantio- and diastereomer. Importantly, the reaction can be run without the need for scrupulously dry solvents or the use of an inert-gas atmosphere.

With optimized conditions in hand, we turned our attention toward the scope of this transformation (Scheme 1). The reaction tolerates a variety of different aldehyde electrophiles, including sterically congested cases such as 2-methylpropanal 2c, cyclohexylcarboxaldehyde $\mathbf{2 d}$ or even pivalaldehyde $\mathbf{2 e}$ (Scheme 1, 3a-e). Notably, all products are obtained in good yields after a short reaction time and essentially as single enantio- and diastereoisomers. A wide range of functional groups, including halides $(\mathbf{3} \mathbf{f}-\mathbf{g})$, protected alcohols $(3 \mathbf{h})$, thioethers $(3 \mathbf{i})$ as well as esters, unsaturated systems and alkynes $(3 \mathbf{j}-\mathbf{l})$ are tolerated under the present reaction conditions. On the alkene component, aromatic and other aliphatic substituents show excellent reactivity $(3 m-p)$ while retaining the same near perfect diastereo- and enantioselectivity. Additionally, products resulting from a nine-membered

Received: November 14, 2018

Published: December 21, 2018 
a) Well-developed asymmetric coupling of aldehydes and alkenes

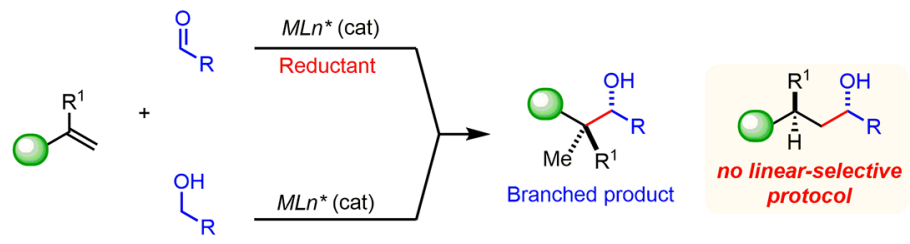

b) Our aim: Development of a linear-selective method allowing the use of unactivated alpha-olefins

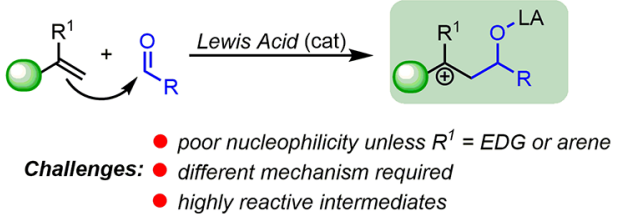

c) This work: Asymmetric linear-selective coupling by a "catch-release" tethering strategy

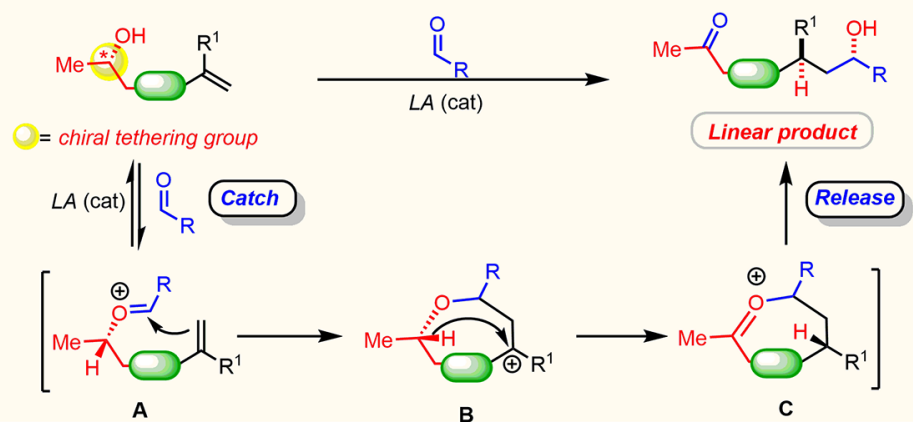

Figure 1. (a) Well-established asymmetric coupling of aldehydes and alkenes. (b) Potential challenges in the development of a linear-selective method. (c) Novel linear-selective, directed asymmetric coupling of aldehydes and alkenes.

Table 1. Selected Optimization of Reaction Conditions

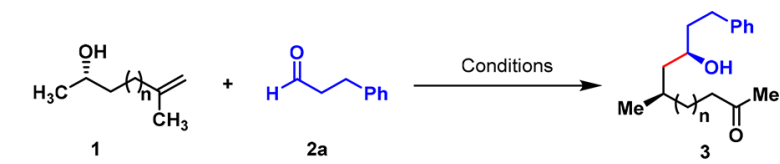

(1a, $n=2 ; 1 b, n=1 ; 1 c, n=3)$

\begin{tabular}{|c|c|c|c|c|c|}
\hline entry $^{a}$ & alcohol & $\begin{array}{c}\text { Lewis acid } \\
(\%)\end{array}$ & $\begin{array}{c}\text { time } \\
\text { (temperature) }\end{array}$ & $\begin{array}{c}\text { yield [\%] } \\
(\mathrm{dr})^{b}\end{array}$ & ee $[\%]^{c}$ \\
\hline 1 & rac-1a & $\mathrm{SnCl}_{4}(20 \%)$ & $1 \min$ (r.t.) & $65(>20: 1)$ & - \\
\hline 2 & $r a c-1 b$ & $\mathrm{SnCl}_{4}(100 \%)$ & $15 \min$ (r.t.) & $<5$ (n.d.) & - \\
\hline 3 & rac-1c & $\mathrm{SnCl}_{4}(20 \%)$ & $1 \mathrm{~h}$ (r.t.) & $25(>20: 1)$ & - \\
\hline 4 & $(S)-1 \mathrm{a}$ & $\mathrm{SnCl}_{4}(5 \%)$ & 3.5 h (r.t.) & $45(>20: 1)$ & $>99 \%$ \\
\hline 5 & $(S)-1 \mathrm{a}$ & $\mathrm{SnCl}_{4}(30 \%)$ & $1 \min$ (r.t.) & $35(>20: 1)$ & $>99 \%$ \\
\hline 6 & $(S)-1 \mathrm{a}$ & $\mathrm{AlCl}_{3}(20 \%)$ & $10 \min$ (r.t.) & trace (n.d.) & n.d. \\
\hline 7 & $(S)-1 \mathrm{a}$ & $\begin{array}{l}\text { TMSOTf } \\
(20 \%)\end{array}$ & 24 h (r.t.) & trace (n.d.) & n.d. \\
\hline 8 & $(S)-1 \mathrm{a}$ & $\mathrm{HCl}(20 \%)$ & $24 \mathrm{~h}$ (r.t.) & trace (n.d.) & n.d. \\
\hline $9^{e}$ & $(S)-1 \mathrm{a}$ & $\mathrm{FeCl}_{3}(20 \%)$ & $10 \min$ (r.t.) & $71^{d}(>20: 1)$ & $>99 \%$ \\
\hline $10^{e}$ & $(S)-1 \mathrm{a}$ & $\mathrm{FeCl}_{3}(5 \%)$ & $5 \min (100$ & $76^{d}(>20: 1)$ & $>99 \%$ \\
\hline
\end{tabular}

${ }^{a}$ Reaction conditions: alcohol $(0.2 \mathrm{mmol})$, aldehyde $(0.24 \mathrm{mmol})$, Lewis acid in dichloromethane (DCM, 0.1 M). ${ }^{b}$ Determined by ${ }^{1} \mathrm{H}$ NMR analysis of the crude reaction mixture. ${ }^{c}$ Determined by chiral stationary phase HPLC. ${ }^{d}$ Isolated yield. ${ }^{e}$ Reaction performed in 1,2dichloroethane (DCE, $0.1 \mathrm{M})$. See SI for further screening of reaction conditions.

intermediate can be accessed in equal selectivities by orthoappending of the bridging charbon chain around an aromatic core $(3 \mathbf{q})$.
The reasons behind the excellent stereoselectivity observed throughout the transformations compiled in Scheme 1 intrigued us from the very first experiments. Scheme 2 depicts our stereochemical model. We assume that the aldehyde $\mathrm{R}$ substituent and the carbinol residue $\mathrm{R}^{1}$ adopt pseudoequatorial orientations during the cyclization event, at which point the first stereogenic center of the product is formed. During the hydride transfer step, ${ }^{11}$ the original chiral element of the substrate is deleted concomitantly with the setting of the second stereogenic center of the product. As hydride transfer must proceed suprafacially, this ensures perfect chirality transfer and rationalizes the excellent stereoselectivities observed even when acetaldehyde, otherwise a challenging aldehyde for enantioselective $\mathrm{C}-\mathrm{C}$ bond forming reactions is employed (3r). ${ }^{12}$ Additionally, an $\alpha$-chiral aldehyde such as $2 \mathrm{~s}$ (i.e., (S)-2-methylbutyraldehyde) is a suitable substrate for this process, allowing the preparation of $3 \mathrm{~s}$ without epimerization of its sensitive chiral center ( 3 s obtained in $71 \%$ yield and $>20: 1$ d.r.). Furthermore, we found that there is a large reactivity difference between aliphatic and aromatic aldehydes, enabling the use of a dialdehyde substrate such as $\mathbf{3 t}$ without the need for protecting group manipulations.

The products of this methodology are chiral diads represented in a range of natural products and bioactive substances. As an example we chose 4, a key intermediate in Maio's study on the synthesis of the neuroactive marine macrolide Palmyrolide A and its analoga (Scheme 3$).{ }^{13}$ In the course of Maio's original work, amide 4 was synthesized from pivalaldehyde (Scheme 3b). The sequence includes a prolineassisted aldol addition, setting the first chiral center. Evans- 
Scheme 1. Scope of the Redox-Neutral Coupling of Aldehydes and Alkenes ${ }^{a}$

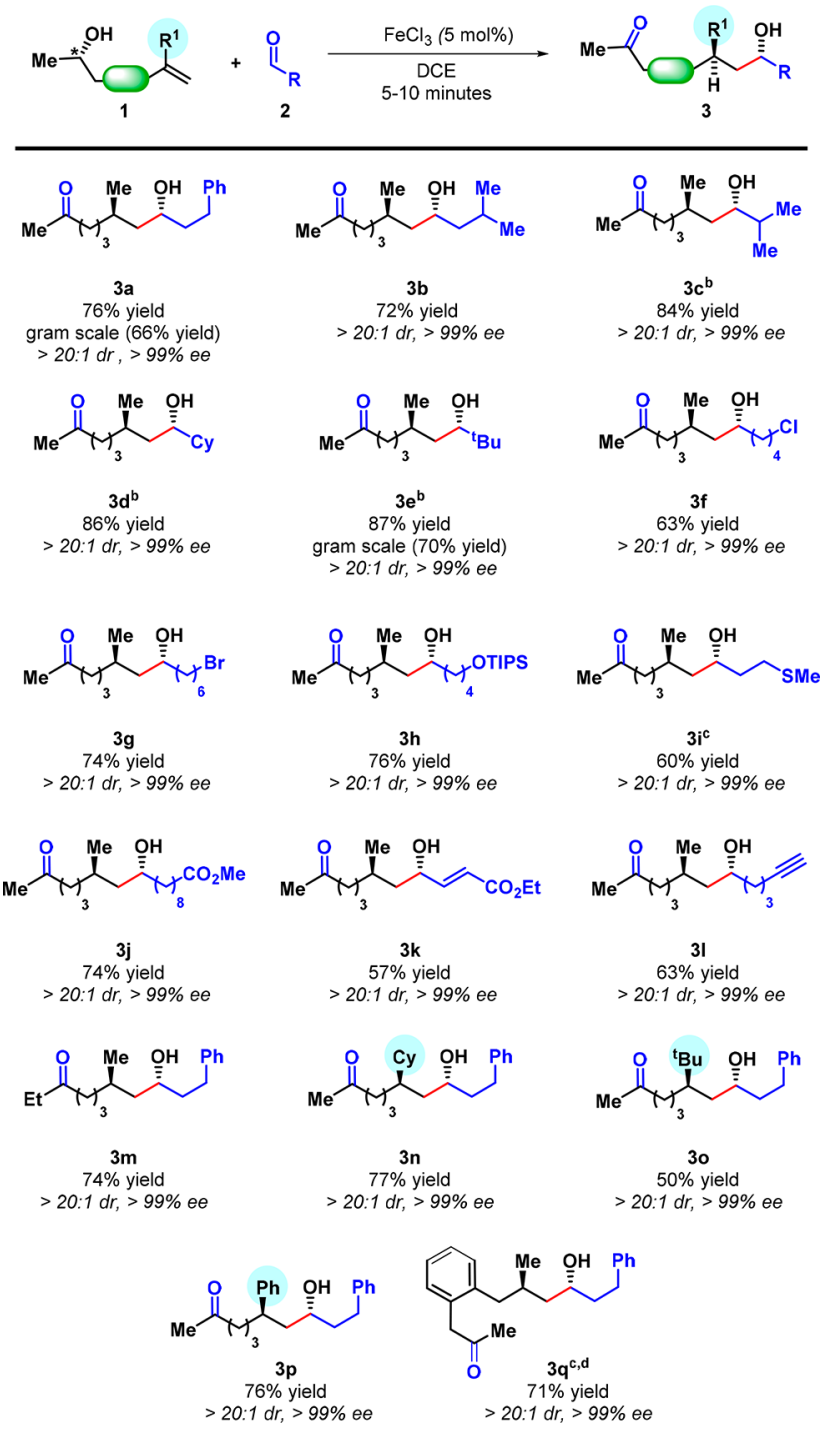

${ }^{a}$ Reaction conditions: alcohol $(0.2 \mathrm{mmol})$, aldehyde $(0.24 \mathrm{mmol})$, $\mathrm{FeCl}_{3}$ (5\% mol), DCE (0.1M), $100{ }^{\circ} \mathrm{C}, 10 \mathrm{~min} .{ }^{b}$ Reaction was conducted at $50{ }^{\circ} \mathrm{C}$ for 10 min. ${ }^{c} 20 \% \mathrm{~mol} \mathrm{FeCl}_{3}$ was used. ${ }^{d}$ Reaction was conducted at room temperature in dichloromethane $(0.1 \mathrm{M})$.

Tishchenko reaction followed by installation of a sulfate ester gives compound 5, which can be converted into 6 via allylation and protection of the alcohol-moiety. Hoveyda-Grubbs metathesis and hydrogenation results in key intermediate 4 in $24 \%$ overall yield. Using the method reported herein, that sequence can be cut in half. Commercially available and cheap $(S)$-propylene oxide was first ring-opened to $\mathbf{1 a}$ in gram-scale. The novel redox-neutral coupling of 1a with pivalaldehyde gives ketone $3 \mathrm{e}$ in good yield and perfect stereochemical outcome. Simple Lieben-haloform reaction ${ }^{14}$ directly followed by amide coupling using standard conditions gives key intermediate 4 in $37 \%$ overall yield over only 4 steps from cheap commercially available materials. In addition, direct comparison of product $\mathbf{4}$ to the material obtained by Maio also allowed unambiguous assignment of stereochemistry to be as shown (C5R, C7S).

In conclusion, we have developed an efficient method to access linear aldehyde/alkene coupling products as essentially
Scheme 2. Proposed Stereochemical Model for the RedoxNeutral Coupling of Aldehydes and Alkenes ${ }^{a}$
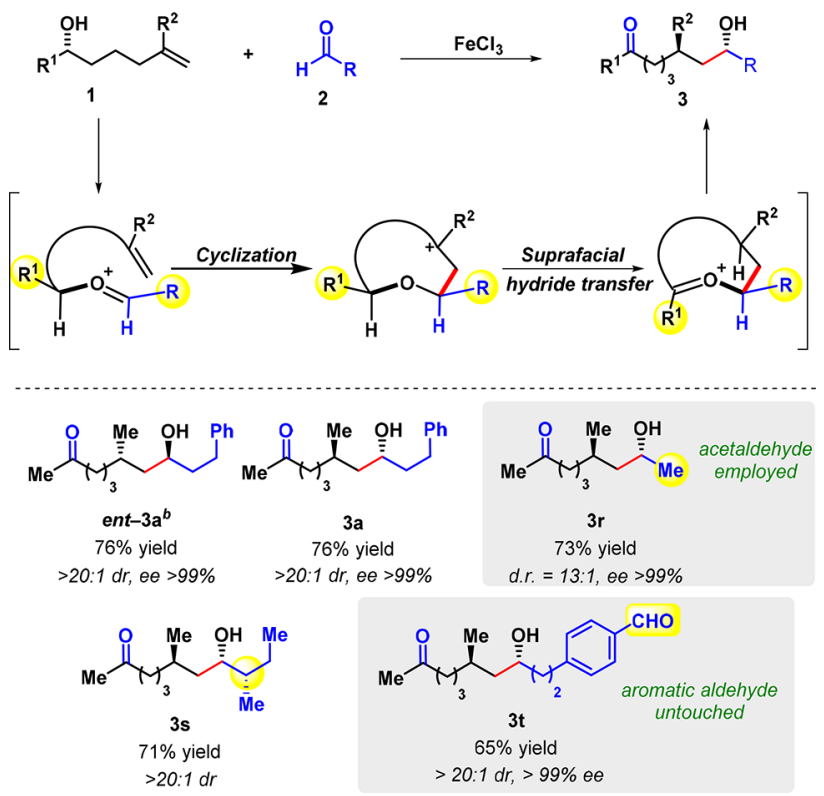

${ }^{a}$ Conditions: $(S)-\mathbf{1 a}\left(0.2 \mathrm{mmol}, 1.0\right.$ equiv), $\mathbf{2}$ (1.2 equiv), $\mathrm{FeCl}_{3}(5 \%$ $\mathrm{mol}), \mathrm{DCE}(2.0 \mathrm{~mL}), 100{ }^{\circ} \mathrm{C}, 5 \mathrm{~min} .{ }^{b}(\boldsymbol{R})-1 \mathrm{a}$ was used.

Scheme 3. Synthesis of Key Intermediate 4 and Determination of the Absolute Configuration

a) Our route: ${ }^{2}$

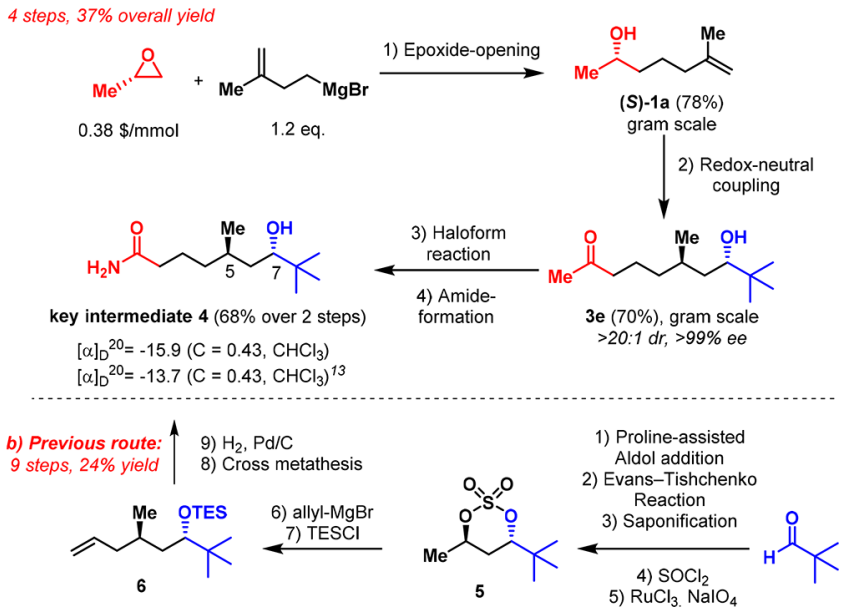

${ }^{a}$ Conditions: (1) (S)-propylene oxide, (3-methylbut-3-en-1-yl)magnesium bromide (1.2 equiv), $\mathrm{CuCN}$ (10 mol \%), THF/ether, $-78{ }^{\circ} \mathrm{C}$ to r.t., $3 \mathrm{~h}$; (2) (S)-1a (1.0 equiv), $2 \mathrm{e}$ (1.2 equiv), $\mathrm{FeCl}_{3}$ (5\% $\mathrm{mol}), \mathrm{DCE}, 50{ }^{\circ} \mathrm{C}, 10 \mathrm{~min}$; (3) iodine (6 equiv), $\mathrm{KI}$ (12 equiv), $\mathrm{KOH}$ (10 equiv), dioxane, r.t., 2 h; (4) DCC (1.2 equiv), HOBt (1.2 equiv), $\mathrm{NH}_{4} \mathrm{OH}$ (2 equiv), DCM, r.t., 3 h.

single diastereo- and enantiomeric materials. An easily accessible chiral alcohol functions as a tether which, by virtue of a "catch-release" process, overcomes the reactivity and selectivity limitations typically associated with olefins as nucleophiles. This method allows the assembly of two chiral centers in near-perfect stereoselectivity, starting from one lone, chiral-pool-derived stereocenter. 


\section{ASSOCIATED CONTENT}

\section{S Supporting Information}

The Supporting Information is available free of charge on the ACS Publications website at DOI: 10.1021/jacs.8b12242.

Characterization data and NMR spectra as well as procedures for preparation of all new compounds (PDF)

\section{AUTHOR INFORMATION}

\section{Corresponding Author}

*nuno.maulide@univie.ac.at

\section{ORCID}

Nuno Maulide: 0000-0003-3643-0718

\section{Author Contributions}

${ }^{\dagger}$ These authors contributed equally.

\section{Notes}

The authors declare no competing financial interest.

\section{ACKNOWLEDGMENTS}

Generous support by the University of Vienna is acknowledged. We are grateful for the support of the ERC (CoG VINCAT) and the Austrian Academy of Sciences (DOC Fellowship to A.P.).

\section{REFERENCES}

(1) Selected reviews on asymmetric coupling of alkenes and carbonyl compounds: (a) Nguyen, K. D.; Park, B. Y.; Luong, T.; Sato, H.; Garza, V. J.; Krische, M. J. Metal-catalyzed reductive coupling of olefin-derived nucleophiles: Reinventing carbonyl addition. Science 2016, 354, aah5133. (b) Holmes, M.; Schwartz, L. A.; Krische, M. J. Acyclic Quaternary Carbon Stereocenters via Enantioselective Transition Metal Catalysis. Chem. Rev. 2018, 118, 6026-6052. (c) Bower, J. F.; Krische, M. J. Formation of $\mathrm{C}-\mathrm{C}$ bonds via iridiumcatalyzed hydrogenation and transfer hydrogenation. Top. Organomet. Chem. 2011, 34, 107-138. (d) Ketcham, J. M.; Shin, I.; Montgomery, T. P.; Krische, M. J. Catalytic enantioselective $\mathrm{C}-\mathrm{H}$ functionalization of alcohols by redox-triggered carbonyl addition: Borrowing hydrogen, returning carbon. Angew. Chem., Int. Ed. 2014, 53, 9142-9150.

(2) (a) Jang, H.-Y.; Huddleston, R. R.; Krische, M. J. Reductive Generation of Enolates from Enones Using Elemental Hydrogen: Catalytic C-C Bond Formation under Hydrogenative Conditions. J. Am. Chem. Soc. 2002, 124, 15156-15157. (b) Huddleston, R. R.; Jang, H.-Y.; Krische, M. J. First Catalytic Reductive Coupling of 1,3Diynes to Carbonyl Partners: A New Regio- and Enantioselective CC Bond Forming Hydrogenation. J. Am. Chem. Soc. 2003, 125, 11488-11489. (c) Bower, J. F.; Patman, R. L.; Krische, M. J. IridiumCatalyzed $\mathrm{C}-\mathrm{C}$ Coupling via Transfer Hydrogenation: Carbonyl Addition from the Alcohol or Aldehyde Oxidation Level Employing 1,3-Cyclohexadiene. Org. Lett. 2008, 10, 1033-1035. (d) Jang, H.-Y.; Huddleston, R. R.; Krische, M. J. Hydrogen-Mediated C-C Bond Formation: Catalytic Regio- and Stereoselective Reductive Condensation of $\alpha$-Keto Aldehydes and 1,3-Enynes. J. Am. Chem. Soc. 2004, 126, 4664-4668. (e) Skucas, E.; Bower, J. F.; Krische, M. J. Carbonyl Allylation in the Absence of Preformed Allyl Metal Reagents: Reverse Prenylation via Iridium-Catalyzed Hydrogenative Coupling of Dimethylallene. J. Am. Chem. Soc. 2007, 129, 1267812679. (f) Kim, I. S.; Ngai, M.-Y.; Krische, M. J. Enantioselective Iridium-Catalyzed Carbonyl Allylation from the Alcohol or Aldehyde Oxidation Level Using Allyl Acetate as an Allyl Metal Surrogate. J. Am. Chem. Soc. 2008, 130, 6340-6341.

(3) Yang, Y.; Perry, I. B.; Lu, G.; Liu, P.; Buchwald, S. L. Coppercatalyzed asymmetric addition of olefin-derived nucleophiles to ketones. Science 2016, 353, 144-150.

(4) Kimura, M.; Ezoe, A.; Shibata, K.; Tamaru, Y. Novel and Highly Regio- and Stereoselective Nickel-Catalyzed Homoallylation of
Benzaldehyde with 1,3-Dienes. J. Am. Chem. Soc. 1998, 120, 40334034.

(5) Lin, H. K.; Tian, L. M.; Krauss, I. J. Enantioselective syn and anti Homocrotylation of Aldehydes: Application to the Formal Synthesis of Spongidepsin. J. Am. Chem. Soc. 2015, 137, 13176-13182.

(6) Zheng, Y. L.; Liu, Y. Y.; Wu, Y. M.; Wang, Y. X.; Lin, Y. T.; Ye, M. C. Iron-Catalyzed Regioselective Transfer Hydrogenative Couplings of Unactivated Aldehydes with Simple Alkenes. Angew. Chem., Int. Ed. 2016, 55, 6315-6318.

(7) (a) Kaldre, D.; Maryasin, B.; Kaiser, D.; Gajsek, O.; Gonzalez, L.; Maulide, N. An Asymmetric Redox Arylation: Chirality Transfer from Sulfur to Carbon through a Sulfonium [3,3]-Sigmatropic Rearrangement. Angew. Chem., Int. Ed. 2017, 56, 2212-2215. (b) Kaldre, D.; Klose, I.; Maulide, N. Stereodivergent synthesis of 1,4-dicarbonyls by traceless charge-accelerated sulfonium rearrangement. Science 2018, 361, 664-667.

(8) (a) MacDonald, M. J.; Schipper, D. J.; Ng, P. J.; Moran, J.; Beauchemin, A. M. A Catalytic Tethering Strategy: Simple Aldehydes Catalyze Intermolecular Alkene Hydroaminations. J. Am. Chem. Soc. 2011, 133, 20100-20103. (b) Orcel, U.; Waser, J. PalladiumCatalyzed Vicinal Amino Alcohols Synthesis from Allyl Amines by in Situ Tether Formation and Carboetherification. Angew. Chem., Int. Ed. 2015, 54, 5250-5254. (c) Orcel, U.; Waser, J. In situ tether formation from amines and alcohols enabling highly selective Tsuji-Trost allylation and olefin functionalization. Chem. Sci. 2017, 8, 32-39.

(9) (a) Blumenkopf, T. A.; Bratz, M.; Castaneda, A.; Look, G. C.; Overman, L. E.; Rodriguez, D.; Thompson, A. S. Preparation of eightmembered cyclic ethers by Lewis acid promoted acetal-alkene cyclizations. J. Am. Chem. Soc. 1990, 112, 4386-4399. (b) Yoshimatsu, M.; Hatae, N.; Shimizu, H.; Kataoka, T. 1,7-Acetal Carbon Rearrangement via 1,5-Hydride Transfer in an Oxocanyl Carbenium Ion. Conversion of O-(5-Hexenyl)-Se,O-heteroacetals or O,O-Acetals into 7-Oxohexanols or 7-Oxohexyl Chlorides. Chem. Lett. 1993, 22, 1491-1494. (c) Ghosh, A. K.; Tomaine, A. J.; Cantwell, K. E. Stereoselective Synthesis of Substituted Oxocene Cores by Lewis Acid Promoted Cyclization. Org. Lett. 2016, 18, 396-399.

(10) For recent examples of $\mathrm{C}-\mathrm{H}$-insertion into carbocations, see: (a) Shao, B.; Bagdasarian, A. L.; Popov, S.; Nelson, H. M. Arylation of Hydrocarbons Enabled by Organosilicon Reagents and Weakly Coordinating Anions. Science 2017, 355, 1403-1407. (b) Popov, S.; Shao, B.; Bagdasarian, A. L.; Benton, T. R.; Zou, L.; Yang, Z.; Houk, K. N.; Nelson, H. M. Teaching an old carbocation new tricks: Intermolecular $\mathrm{C}-\mathrm{H}$ insertion reactions of vinyl cations. Science 2018, $361,381-387$.

(11) For reviews on hydride-transfer reactions, see (a) Haibach, M. C.; Seidel, D. C-H Bond Functionalization through Intramolecular Hydride Transfer. Angew. Chem., Int. Ed. 2014, 53, 5010-5036. (b) Peng, B.; Maulide, N. The Redox-Neutral Approach to C-H Functionalization. Chem. - Eur. J. 2013, 19, 13274-13287. (c) Deno, N. C.; Peterson, H. J.; Saines, G. S. The Hydride-Transfer Reaction. Chem. Rev. 1960, 60, 7-14. (d) Pan, S. C. Organocatalytic C-H activation reactions. Beilstein J. Org. Chem. 2012, 8, 1374-1384. For selected examples, see: (e) Chen, W. J.; Ma, L. L.; Paul, A.; Seidel, D. Direct $\alpha-\mathrm{C}-\mathrm{H}$ bond functionalization of unprotected cyclic amines. Nat. Chem. 2017, 10, 165-169. (f) Mori, K.; Kurihara, K.; Yabe, S.; Yamanaka, M.; Akiyama, T. Double C(sp3)-H Bond Functionalization Mediated by Sequential Hydride Shift/Cyclization Process: Diastereoselective Construction of Polyheterocycles. J. Am. Chem. Soc. 2014, 136, 3744-3747. (g) Saito, K.; Akiyama, T. Chiral Phosphoric Acid Catalyzed Kinetic Resolution of Indolines Based on a Self-Redox Reaction. Angew. Chem., Int. Ed. 2016, 55, 3148-3152. (h) Bauer, A.; Maulide, N. A Stereoselective Reductive Hosomi-Sakurai Reaction. Org. Lett. 2018, 20, 1461-1464. (i) Gandamana, D. A.; Wang, B.; Tejo, C.; Bolte, B.; Gagosz, F.; Chiba, S. Alkyl Ethers as Traceless Hydride Donors in Brønsted Acid Catalyzed Intramolecular Hydrogen Atom Transfer. Angew. Chem., Int. Ed. 2018, 57, 6181-6185.

(12) Yang, J. W.; Chandler, C.; Stadler, M.; Kampen, D.; List, B. Proline-catalysed Mannich reactions of acetaldehyde. Nature 2008, 452, 453-455. 
(13) Tello-Aburto, R.; Newar, T. D.; Maio, W. A. Evolution of a Protecting-Group-Free Total Synthesis: Studies en Route to the Neuroactive Marine Macrolide (-)-Palmyrolide A. J. Org. Chem. 2012, 77, 6271-6289.

(14) Lieben, A. The formation of iodoform and the application of this reaction in the chemical analysis. Liebigs Ann. Chem. 1870, 7, 218-236. 